\title{
A maneira correta de entrar no círculo: A questão do sentido em Ser e Tempo*
}

\author{
The correct way to enter the circle: \\ The question of meaning in Being and Time
}

\author{
Prof. Dr. Ramón Rodríguez \\ ramon@filos.ucm.es \\ Universidad Complutese - Madrid \\ tradução** Rebeca Furtado de Melo
}

\section{O problema metodológico de Ser e tempo}

As reflexões metodológicas de Ser e tempo são em seu conjunto bastante parcas e de volume escasso frente ao conteúdo esmagador das análises concretas que desempenham os "existenciais". Provavelmente esta precariedade é fruto da oposição de Heidegger à primazia do método na ciência e na filosofia modernas e a consequente esterilidade das considerações metodológicas vazias, o que casa bem com sua atitude fenomenológica de que todo o método descansa no trato com seu objeto, na doação da coisa mesma. Sabemos, contudo, das preocupações metodológicas que embargam a hermenêutica fenomenológica da facticidade ${ }^{1}$, centradas na necessidade de lograr um acesso direto à vida fática, preocupação que segue bem presente em Ser e tempo, com a que se abre à exposição do programa geral da obra e das diversas tarefas que a compõe. A primeira e fundamental, uma vez localizado o ente que vai ser o "primariamente interrogado", o Dasein, estabelece a "explícita apropriação e asseguramento da forma direta de acesso (Zugangsart) a ele". Nela consiste todo o problema metódico específico dessa tarefa preparatória da questão do ser que é a analítica ontológica do Dasein. O famoso $§ 7$ da Introdução se endereça a enfrentá-la, mas também às múltiplas reflexões metódicas ocasionais que Heidegger deixa aparecer, aqui e ali, no desenvolvimento da análise. Existe, contudo, uma diferença significativa entre o $\S 7$ e as considerações posteriores, nas quais Heidegger, ao iniciar cada nova etapa da investigação, retoma os passos dados e reflete sobre o obtido e o que falta por elucidar. Certamente, no texto da Introdução, Heidegger dedica várias páginas ao "método fenomenológico da investigação", mas, sem subestimar de modo algum a sua importância, a apresentação de tal

1 Permito-me a remissão para este tema ao meu livro La transformación hermenéutica de la fenomenología. Una interpretación de la obra temprana de Heidegger, Madrid, Tecnos, 1997.

\footnotetext{
* Este trabalho foi realizado no marco do projeto de investigação "Interpretação e verdade na hermenêutica fenomenológica" (FFI2009 - 11921), financiado pelo Ministério de Ciência e Inovação espanhol, do qual o autor é o pesquisador principal.

** NT: Este trabalho foi originalmente publicado em: A. Rocha de la Torre (ed.), Heidegger hoy, Buenos Aires/Bogotá, Gramma Ediciones/Editorial Bonaventuriana, 2011, páginas 305-327./E-mail da tradutora: rebecafurtado7@gmail.com.
} 
método acaba por ser demasiadamente abstrata e pouco ilustrativa, tanto ao precisar os problemas metodológicos que a análise deve enfrentar, como do modo concreto no qual, em seguida, em seu desenvolvimento, se exerce o método fenomenológico-hermenêutico. Ao contrário, o que chama a atenção das reflexões metódicas posteriores, como, por exemplo, as dos $\S 45$ e $\S 63$, é que todas elas giram em torno das dificuldades que a estrutura prévia do compreender representa para a analítica ontológica. A forma inevitavelmente circular que a antecipação de sentido constitutiva do poder-ser do Dasein obriga à investigação tomar e que força a perguntar-se, após cada etapa cumprida: o que logramos até agora e com que grau de credibilidade fenomenológica? É o conjunto de problemas ligados ao "círculo do compreender", que curiosamente não aparece, nem sequer como impedimento, na exposição do $\S 7$, o que absorve a preocupação metodológica de Heidegger. Uma preocupação metodológica que surge, não da objeção lógico-formal do circulus in probando, que Heidegger vê com claridade que não lhe afeta e que no fundo deixa de lado, senão, a meu entender, da dificuldade intrínseca que leva consigo encaixar, no princípio básico da fenomenologia, um proceder analítico no qual impera a antecipação de uma ideia diretriz, provisional e não consolidada, e uma desfiguração constante do sentido dos fenômenos que se analisam.

Tal problemática está claramente esboçada nas breves explicações do que significa a primazia ôntico-ontológica do Dasein que realizam os $\S 4$ e $\S 5$. Aí Heidegger expõe que o destino da investigação sobre o sentido de ser é pendente da elucidação do fenômeno de ser, isto é, daquele âmbito no qual o ser se manifesta como tal, a compreensão de ser, que ao ser um "comportamento" de um ente determinado, o homem concreto que somos cada um de nós, faz com que se determine a este aí-do-ser (Da-sein). A compreensão de ser, como fenômeno de ser, é então a única base possível de todo o discurso acerca do ser (ontologia), daí a importância de depurar com um mínimo de precisão o que a compreensão de ser comporta e oferece. Depurar e precisar é a tarefa filosófica, ontológica, que opera tomando o estado bruto, tal como se encontra, o fato imediato da compreensão dada que, por isso, deve ser denominada pré-ontológica. Contudo, converter a compreensão em tema explícito de investigação é o mesmo que fazer o ser do Dasein, a que pertence, objeto temático de estudo, daí que a ideia de que a analítica existencial do Dasein, que se propõe trazer à luz sua estrutura ontológica, seja a Ontologia Fundamental que abre o terreno de toda ontologia (HEIDEGGER, Ser e tempo, p. 13)². Com isso, porém, a situação

$2 \mathrm{O}$ giro ontológico que Heidegger imprimiu, ao final de seu primeiro período de docência em Freiburg, à hermenêutica fenomenológica da facticidade, seu primeiro programa filosófico, 
metódica não se transforma em absoluto: a única fonte de onde deve manar a análise do ser do Dasein é a mesma que a da questão do ser em geral: a compreensão pré-ontológica de seu próprio ser, imiscuída e entretecida naquela. Como tratar a compreensão pré-ontológica é, assim, o problema metódico essencial: o acesso direto ao Dasein, que o define, é sinônimo do uso direto que a investigação faz do que lhe é dado na compreensão pré-ontológica e é este uso o que determina todas as dificuldades da análise existencial. O $\S 5$ não indica outra coisa, de maneira inicial e preliminar, ao dizer que a proximidade ôntica que o Dasein tem a si mesmo - pois é sempre o ente que cada Dasein concreto e a investigação ontológica mesma têm mais próximo -, não leva acoplada uma imediatidade de caráter similar indubitável na doação prévia de seu tipo de ser. A compreensão pré-ontológica de seu ser, que é um fato igualmente imediato e dado com essa proximidade ${ }^{3}$, oferece um sentido que não está garantido por seu simples mostrar-se e que não pode tomar-se, por isso, como "o fio condutor adequado” da investigação. A conviç̧ão de que a primazia ôntico-ontológica

cujo resultado é a Ontologia Fundamental que Ser e Tempo apresenta, frequentemente não tem sido bem entendido. A reivindicação de uma proposta radicalmente ontológica, contra a tradição epistemológica do neokantismo, que Heidegger leva a cabo, unida a seu constante trabalho acadêmico em torno de Aristóteles, parece aproximá-lo à concepção clássica de "ontologia", a ciência do ente enquanto ente e de suas primeiras causas e princípios. A ideia, bastante difundida, de que o projeto de Ser e Tempo buscaria alcançar a uma ontologia geral ("a questão do ser") através da análise do tipo de ser de um determinado ente (o Dasein ou existente humano) assume implicitamente esta proximidade, atribuindo a ele as mesmas pretensões da ontologia clássica, apenas com uma novidade "moderna" da analítica da existência. Contudo, é evidente, a partir da própria introdução de Ser e Tempo, que a pergunta diretiva pelo sentido de ser e a analítica existencial que a desenvolve, centrada no fato da compreensão de ser, estão muito longe da ontologia, em um sentido tradicional. Não há nada nelas que equivale propriamente ao que constitui o conteúdo da ontologia. Nem a pergunta pelo sentido de ser aponta a estabelecer os princípios gerais do ente, nem a analítica do Dasein é algo assim como uma ontologia regional que delimite com precisão os caracteres ônticos da realidade humana. A pergunta pelo sentido de algo, como veremos adiante, se refere à manifestabilidade desse algo, por isso a pergunta pelo sentido de ser indaga de modo que todo o que é se faz presente; a partir desta indagação se olha ao Dasein, que, portanto, é visto apenas como o lugar da manifestação de ser e, desta maneira, se leem alguns de seus traços ônticos, aqueles justamente que parecem conformar a compreensão de ser. Isto determina que, ainda que Heidegger faça, em relação ao Dasein, abundante uso de expressões nitidamente ontológicas como Seinsverfassung (constituição ontológica) ou Seinsbestimmheit (determinação ontológica), tais expressões não omitem as características ônticas definitórias de uma determinada essência (ainda que possam ser lidas assim também), senão rasgo onto-lógicos, quer dizer, o que no Dasein diz o ser, o que nele há de manifestação ou acesso ao ser. É a mirada à fenomenalidade, ao aparecer do ser, o que determina a peculiaridade da "ontologia" heideggeriana e o que a carrega de uma constante ambivalência, pois nela "ser" e fenômeno de ser" são tratados correlativa e inseparavelmente. A ontologia só é possível como fenomenologia: esta taxativa afirmação de Ser e Tempo contém a chave de todo sua proposta da "ontologia". Para esta questão das relações entre a ontologia clássica e a proposta heideggeriana, ver o excelente livro de Alejandro Vigo, Arqueologia e aletheiologia, Buenos Aires, Biblos, 2008, especialmente os lúcidos estudos 5 e 10.

3 Na realidade, a compreensão pré-ontológica de seu próprio ser é a mesma proximidade ôntica, pois o Dasein está próximo de si mesmo na forma peculiar que determina não ser simplesmente um ente na identidade inerte e muda da pedra, mas, ao contrário, aberto a seu próprio estar aí e essa abertura é já sua compreensão pré-ontológica. 
do Dasein, baseada na compreensão pré-ontológica, é a única base disponível para a análise e, ao mesmo tempo, a fonte fundamental de seus perigos e distorções, determina as ondas sucessivas de problemas metódicos com que se encontra o programa de Ser e tempo. "O Dasein é onticamente para si mesmo o mais próximo, ontologicamente o mais distante, mas, ainda assim, pré-ontológicamente não estranho" (HEIDEGGER, Ser e tempo, p. 16). Esta conhecida expressão de Heidegger, tantas vezes repetida, encerra um único fenômeno, um único dado positivo: a abertura ao próprio ser que leva consigo o fato mesmo de existir como Dasein, humanamente, e que por sua ambiguidade intrínseca (sua estranheza e familiaridade simultâneas, como diria Gadamer) necessidade de uma cuidadosa aproximação fenomenológica. A circularidade dessa aproximação se funda em que ela é o único e insuperável dado inicial, ao que há que se voltar uma e outra vez. Na compreensão pré-ontológica está sempre dado aquilo ao que se quer chegar e não poderia ser de outro modo: de onde, se não, a reflexão filosófica poderia sacar algo assim como o ser do Dasein? De uma livre aventura especulativa?

\section{Fenomenologia e círculo do compreender}

Como se recordará, o círculo do compreender não é em Ser e Tempo uma forma de análise, nem um modo de conhecimento, nem um problema de método, mas, ao contrário, "a expressão da estrutura antecipativa (Vorstruktur) ontológico-existencial do Dasein". Tanto que a estrutura ontológica é, dentro de certos limites, epistemologicamente neutra, pelo que não se traduz mecanicamente em uma determinada metodologia. Por isso, Heidegger mostra que o decisivo não é saltar para fora do círculo, senão "entrar nele da maneira correta". Se o círculo ontológico tivesse uma tradução epistemológica imediata e unívoca seria supérfluo perguntar-se pela maneira correta de entrar nele. O problema metódico surge aqui, quando, diante das diversas possibilidades de enfrentar o caráter antecipativo do poder-ser, a analítica do Dasein, que é uma tarefa científica, se pergunta qual é a forma correta de propor uma investigação que trata de indagar sobre o sentido de ser de um ente peculiar. E a resposta de Heidegger, a saber, "assegurar o caráter científico do tema mediante a elaboração da estrutura prévia a partir das coisas mesmas", não deixa dúvidas: $a$ fenomenologia é a forma correta de entrar no círculo. Longe de que o círculo hermenêutico, como topicamente se diz, suponha uma objeção definitiva contra a fenomenologia, esta é a única forma de exercê-lo conscientemente, a que ga- 
rante a validade e a solvência de uma tarefa filosófica que sabe de sua condição finita. A partir deste ponto de vista, se quis manter que os momentos metódicos mais propriamente hermenêuticos de Ser e Tempo estão dirigidos, demarcados e limitados pelo princípio da fenomenologia (que seja o dar-se originário da coisa quem marque o conteúdo e o modo do discurso), ao que Heidegger se esforça em manter-se fiel e que são, por isso, um exponente de hermenêutica fenomenológica em exercício. Tais momentos são fundamentalmente dois: $o$ conceito de sentido ligado à estrutura da pré-compreensão e a crítica das desfigurações do fenômeno que se analisa, a saber, a autocompreensão do Dasein. Neste trabalho me ocuparei, por razões de espaço, somente do primeiro.

"O conceito preliminar de fenomenologia" do $\S 7$ dava as duas indicações essenciais para tratar ambos os momentos, que formam inescapavelmente parte do "caráter metódico da analítica existencial" que explica o § 63. 1) Aí ficava perfeitamente claro que o conceito fenomenológico de fenômeno, frente ao formal, geral e o vulgar, o constitui:

aquilo que de um modo imediato e regular precisamente não se mostra, aquilo que fica oculto no que imediata e regularmente se mostra, mas que ao mesmo tempo é algo que pertence ao que imediata e regularmente se mostra, até o ponto de constituir seus sentido e fundamento (HEIDEGGER, Ser e tempo, p. 35).

E isso é justamente o ser, que se encontra nos entes que se mostram (nos comportamentos ônticos, no caso do Dasein), mas que não se reduz aos traços deste. Mas não menos claro ficava que tal conceito fenomenológico, como aplicação que desformaliza o conceito formal, supõe a vigência deste: apenas se o que regularmente não se mostra pode vir a mostrar-se como ele mesmo, tem sentido o trabalho de interpretação, que não é outra coisa que a tentativa de trazer a tona o fenômeno. 2) Por sua vez, o texto ressalta que, das formas de estar oculto o ser nos entes que imediatamente se mostram, "a 'dissimulação' (Verstellung) é a mais frequente e perigosa, porque as possibilidades de engano e desvio são aqui particularmente tenazes" (HEIDEGGER, Ser e tempo, p. 36). Com isso Heidegger assentava as bases, de maneira geral, das relações entre o ôntico-existenciário e o ontológico-existencial: o que a analítica existencial persegue é trazer à luz o ser do Dasein a partir das bases fenomênicas dos comportamentos ônticos - "o que no início e da maioria das vezes se mostra” -, ser 
que se encontra essencialmente dissimulado, desfigurado, no sentido imediato desses comportamentos. Daí que as estruturas ontológicas tenham que ser arrancadas dos fenômenos, o que exige assegurar "o ponto de partida, o modo de acesso e o trânsito através das ocultações dominantes" (ibidem). Porém, um pouco mais a diante, quando se trata de precisar o cometido da ontologia fundamental que é a analítica existencial, Heidegger afirma enigmaticamente que "da investigação mesma se desprenderá que o sentido metódico da descrição fenomenológica é exegese (Auslegung)" (HEIDEGGER, Ser e tempo, p. 37). A afirmação acaba sendo enigmática porque, abruptamente enunciada neste contexto, não se sabe se afeta todo o tratamento dos fenômenos ou apenas a passagem, através das ocultações, a partir da base fenomenológica já dada ao ser "dissimulada". A remissão ao conceito grego de hermenéuein como anunciar ou dar a conhecer nada explicita do sentido que se deve atribuir propriamente à "interpretação". Diria-se que Heidegger renuncia a explicar de modo teórico e preliminar no que consiste o momento especificamente hermenêutico do método até que a análise fenomenológica traga à luz a estrutura do "compreender" (HEIDEGGER, Ser e tempo, §32), sem a que dificilmente pode realizar-se, e, sobretudo, para deixar que seja seu exercício efetivo quem o ponha em manifesto. Por isso, o texto diz claramente "da investigação mesma se depreenderá..." (e não de uma prévia exposição teórica).

\section{O conceito hermenêutico de sentido como problema fenomenológico}

\subsection{Sentido e manifestabilidade. A continuidade fenomenológica de Husserl a Heidegger}

Em um conhecido trabalho dos anos setenta do século passado, que segue proporcionando uma boa orientação inicial a quem busca entender as relações entre fenomenologia e hermenêutica, Paul Ricoeur apontava que "o mais fundamental pressuposto fenomenológico de uma filosofia da interpretação é que toda questão que verse sobre um ente qualquer é uma questão sobre o sentido deste "ente" "4. Esta é uma sentença perfeitamente justa, desde que se interprete a noção de sentido em seus termos precisamente fenomenológicos e não se generalize levando-a para concepções puramente semânticas de sentido, coisa que

4P. Ricoeur, "Phénoménologie et herméneutique: en venant de Husserl...", em Du text à l'action, Paris, Seuil, 1986, p. 61. 
com frequência ocorre na filosofia hermenêutica atual. Pois, em efeito, o que me parece necessário destacar é que a noção de sentido que Heidegger expõe no $\S 32$ de Ser e Tempo, no qual o sentido aparece vinculado à estrutura prévia do compreender, não é outra coisa que um desenvolvimento da ideia geral de sentido que Husserl constantemente usou em Ideias I.

O característico desta noção husserliana é sua permanente dependência do puro aparecer do que aparece. Já nas Investigações Lógicas descrevia os atos de dar sentido que determinam uma expressão como tal expressão, frente aos atos que nela constituem o simples som físico articulado, como aqueles atos "nos quais estamos voltados exclusivamente para o objeto que aparece neles, nos quais pomos a vista nele, o mencionamos em um sentido especial, estrito" (LU, $\mathrm{V}, \S 19)$. O sentido que esses atos proporcionam consiste, pois, em que neles aparece um objeto preciso intencional, um algo que se mostra como tal coisa determinada. A mesma ideia é reforçada, na sexta investigação, pelo conceito de sentido apreensivo: "como a matéria indica, por assim dizer, o sentido em que é apreendido o conteúdo representante, podemos falar também de sentido apreensivo" (LU, VI, §26). A matéria, aquele ingrediente do ato que é responsável pela concreta direção intencional a um objeto em sua forma específica de aparecer $^{5}$, determina como que é tomado o conteúdo representante (as sensações), quer dizer, faz com que o ato seja uma apresentação efetiva de um objeto que aparece nele. Este aparecer do objeto constitui então o sentido apreensivo do ato. É, portanto, claro que o "sentido" é uma noção que expressa o aparecer determinado e concreto de algo em um ato intencional.

As Ideias I dão uma formulação inequívoca para esta noção fenomenológica de sentido. A essência de toda vivencia intencional é, frisa o $\S 88$, "acolher uma coisa como a que chamamos 'sentido", conceito que fica perfeitamente explícito quando Husserl acrescenta:

pelo qual há que tomar o correlato noemático, que aqui se chama 'sentido' (em uma significação muito ampla), exatamente tal como se apresenta imanente na vivência da percepção, do juízo, do gosto etc., quer dizer, tal como, se nos limitamos a perguntar à vivência, nos é oferecido por ela. (E. HUSSERL, Hua III/1, 18)

$5 \mathrm{Na}$ linguagem técnica das Investigações lógicas: a matéria é responsável não apenas pelo objeto que é intencionado, mas, também do objeto tal como é intencionado. 
Esta amplíssima noção de sentido, que se faz equivaler ao que aparece enquanto tal, "o percebido (imaginado, recordado, etc.) enquanto tal" (e que é, na economia das Ideias, a base para todas as ulteriores distinções no seio do noema) é a que se encontra no plano de fundo do pensamento heideggeriano e a que se faz inteligível no uso abundante da noção de sentido que domina os escritos de Heidegger em torno de Ser e Tempo. Quando ele se pergunta "o que é o percebido enquanto tal" (das Wahrgenommene als solches, HEIDEGGER, GA, 20, p. 53), se interroga, o mesmo que Husserl, pelo Wahrnemungssinn, pelo sentido perceptivo: não se refere aos traços meramente ônticos do objeto, a seus predicados reais, mas, ao contrário, ao que aparece na percepção justamente na medida em que aparece assim nela. Todo o que se deixa ver na estrutura do que parece puramente enquanto aparece forma parte do sentido da vivência ou, para dizê-lo em termos heideggerianos, do comportamento, seja perceptivo ou de outro tipo.

Duas observações nos permitem compreender esta continuidade fenomenológica no uso heideggeriano da noção de sentido. A primeira, que a vinculação do sentido ao âmbito do aparecer não comporta ter-se instalado na redução fenomenológica e em seus pressupostos idealistas. Certamente, o conceito de sentido de Ideias I ao que aludido é posterior à Meditação fenomenológica fundamental que assenta a redução e o caráter absoluto e separado da consciência, mas o que aparece como tal em um determinado comportamento (o sentido nessa "significação muito ampliada") é suscetível de ser destacado mediante uma descrição direta do imediatamente vivido nele. Não é necessário prescindir do existir fático, do comportamento concretamente exercido, para acender a correlação essencial entre a percepção e o que aparece nela, para que venham à tona os momentos estruturais do sentido. Isto é algo que forma parte do exercício fenomenológico que Heidegger realizou desde o início com a análise do mundo circundante (Umwelterlebnis). Essa descrição, balizada pelo sentido vivido, aos modos de aparecer das coisas e de nossa posição com respeito a elas, é muito anterior às possíveis interpretações do sentido como a formação resultante (Leistungsgebilde) de complicadas funções intencionais de dar sentido, como Husserl o concebe posteriormente (por exemplo, em Hua, VIII, 247). A esta discussão agora não importa senão apenas destacar que a noção de sentido é consubstancial à descrição fenomenológica dos comportamentos e se estende a todo o terreno da intencionalidade latamente entendida. Isso permite a Heidegger utilizá-la em todas as suas análises da vida fática primeiro e do ser do mundo depois.

Nada resulta mais ilustrativo da concepção fenomenológica do sentido que impera no pensamento de Heidegger que a expressão, tantas vezes utilizada por 
ele, do "ente no como de seu estar descoberto (das Seiende im Wie seiner Endecktheit)", pois dizer que algo se encontra no modo de estar descoberto - que está manifesto, patente - é o mesmo que dizer que constitui o sentido do comportamento em que se torna patente, pois se limita a aparecer nele, a mostrar-se como tal. Por isso Heidegger não tem nenhuma dificuldade de tornar simplesmente as coisas equivalentes em seu modo de estar descobertas, atribuindo esta equivalência à atitude pré-fenomenológica do mundo grego, para a qual os entes e os fenômenos diziam exatamente o mesmo: "os 'fenômenos' é a totalidade do que pode ser posto à luz do dia, o que os gregos por vezes identificavam simplesmente com ta ónta, os entes" (HEIDEGGER, Ser e Tempo, p. 28; Cf. ibid., 219). O mesmo acontece com a noção fenomenológica geral de "coisa mesma", cujo sentido não expressa nada mais que o fato de algo, um ente, se faz patente ele mesmo em alguma forma de manifestação. A "coisa mesma" é o sentido de um ato na medida em que este se refere ao ente em si mesmo e não a uma representação sua, com independência de que o ato simplesmente o omita ou o apresente em "carne e osso".

A partir deste ângulo, deve-se entender a noção central da proposta inteira de Ser e Tempo: a questão do sentido de ser. Apesar de que suas primeiras linhas, com a famosa citação de $O$ Sofista, situem a pergunta no âmbito do significado da palavra "ser", situação que é reforçada pela imediata discussão dos preconceitos tradicionais em torno do conceito de ser (§ 1), a pergunta pelo sentido de ser não aponta para a tarefa de precisar o significado ou o conteúdo semântico de um termo tão gasto como ambíguo, por mais que às vezes, a indagação comece por catalogar seus usos e contextos linguísticos, senão a algo mais radical, que é uma genuína tarefa filosófica: investigar o âmbito em que qualquer coisa que é, com sua estrutura e modo de ser, se faz presente, vem à manifestação como tal. Após ter elucidado a noção geral de sentido, da qual logo falaremos, Heidegger a leva em direção à pergunta pelo ser e aponta: "E quando perguntamos pelo sentido do ser, a investigação não se torna por isso profunda, nem submerge em algo que estivesse detrás do ser, mas, ao contrário, pergunta por ele mesmo, na medida em que está inscrito na compreensibilidade do Dasein. O sentido de ser nunca pode ser contraposto ao ente ou ao ser como "fundamento" sustentador do ente, porque "fundamento" é acessível apenas como sentido, ainda que apenas seja como o abismo do sem sentido" (HEIDEGGER, Ser e Tempo, p. 152). Sentido de ser não é, portanto, um campo de investigação linguística que tivesse por tema o catálogo de possíveis significados do conceito de ser; nem tampouco um âmbito de investigação ontológica, no sentido tradicional, que buscaria, no ser real das coisas, o estrato ontológico profundo de seus princípios 
ou fundamentos. Trata-se de algo, de certo modo, mais elementar, ainda que não, mais simplório, anterior à imersão direta na estrutura ontológica do que é: de perguntar pelo modo como qualquer tipo de ente, qualquer forma do que, em geral, dizemos que é, se faz compreensível, se dá a conhecer como tal, se manifesta. "Quando dizemos que um ente 'tem sentido', isso significa que se fez acessível em seu ser." (HEIDEGGER, Ser e tempo, p. 324). O ser não se opõe, portanto, ao sentido como se tratasse de dois âmbitos ônticos diferentes, dois regiões distinguíveis dentro do "que há", mas, ao contrário, o sentido é um ser mesmo enquanto manifestação, acessível à compreensão.

Esse último nos leva diretamente à segunda observação, que se desprende desta vinculação do "sentido" a manifestabilidade do ente: o sentido, nesta acepção fenomenológica primária que dirige toda a concepção heideggeriana, guarda uma relação muito escassa com o que no campo das teorias lógicas dominantes da época, desde Lotze a Husserl, passando pelo neokantismo, se estimava como o reino do sentido: um âmbito ideal de significado, distinto do ser psíquico do ato e do ser real dos objetos ou estados de coisas. Essa região intermediária, instituída para dar conta da diferença essencial entre a permanente identidade e a validade do conteúdo do juízo frente a cambiante diversidade dos correspondentes atos concretos de julgar (Urteisfällungen), é a única possibilidade de recorrer a especificidade do sentido, que é entendido então como a unidade ideal de significação presente em todo enunciado, especificidade para a qual é cega toda forma de naturalismo ${ }^{6}$. Ainda que a posição de Heidegger seja obviamente crítica em relação a esta concepção de sentido, o fundamental para nosso propósito não é entrar nos pormenores e no alcance desta crítica, senão destacar que esse âmbito ideal de sentido, caso fosse necessário mantê-lo, é absolutamente distinto e posterior ao sentido como manifestabilidade. Sobretudo, porque, como disse antes, o sentido não demarca, por assim dizer, um âmbito de ser, mas, ao contrário, indica tão apenas que o ser, um âmbito de ser ou um ente são acessíveis, que se encontram na situação de estar mani-

6Na exposição da crítica husserliana ao psicologismo, contida no curso de 1925-1926 Logik. Der Frage nach der Wahrheit, Heidegger apontou como um dos palanques básicos da crítica "a distinção fundamental entre o ser real do ato de julgar e a validade ideal do conteúdo julgado" (GA, 21, 47). Heidegger identifica essa validade com o sentido: "O poder do naturalismo [...] tem sua raiz em uma cegueira para o não real: o conteúdo proposicional como tal, o sentido, o ser ideal" (Ibidem, 50). Em Ser e Tempo, que recolhe, sem uma tão pormenorizada discussão, os resultados da crítica à interpretação logicista do discurso enunciativo, tem claras evidencias do distanciamento do conceito fenomenológicohermenêutico de sentido com respeito a essa concepção própria do que Heidegger chama a Geltungslogik (lógica da validade); assim, por exemplo, ao iniciar o tratamento do enunciado, nos avisa: "Na medida em que o enunciado (ou o 'juízo') se funda no compreender e representa uma forma derivada de levar a cabo a interpretação, ele também tem um sentido. Contudo, o sentido não pode ser definido como algo que se encontra 'no' juízo junto com o ato de julgar" (HEIDEGGER, Ser e tempo, pp. 153 - 154). 
festos, de ser inteligíveis. E a manifestabilidade não comporta, de entrada, um âmbito ou região especial oposta a outras, mas, ao contrário, a possibilidade mesma de que algo, seja o que for, seja compreensível. Mas é que, além disso, supor que o sentido é um conteúdo ideal ligado ao enunciado ou, em geral, à expressão verbal, supõe negar toda forma de experiência antepredicativa a possibilidade de dar a entender algo, descartar de entrada que os entes ou o mundo mesmo possam manifestar-se em formas de comportamento não estritamente verbais. O conceito fenomenológico-hermenêutico de sentido que Ser e Tempo desenvolve se opõe - este é o ponto crucial - a que o modelo lógico-verbal se constitua na forma originária de manifestação de algo, a que o enunciado seja a via de ingresso na compreensibilidade. Contudo, a partir daqui, há muitos problemas abertos a discutir. O fundamental deles, certamente, consiste nessa manifestabilidade própria do sentido. À interpretação logicista, como qualquer tentativa de indagar sobre esse problema, se agrega a razão fundamental de que a coisa, enquanto manifestada, diz algo mais que a coisa em seu absoluto ser próprio: seu estar manifestada não é um predicado real seu; mas em que consista essa manifestabilidade - se é uma propriedade de outra ordem da coisa, se é algo alheio a ela ou se é um rendimento da consciência - não está decidido de antemão. E é a esta indecisão, que deixa aberta sua consistência ontológica, ao que se atém o uso heideggeriano primário de sentido.

\subsection{A inflexão hermenêutica do sentido}

O tratamento explícito da ideia de sentido que realizam os parágrafos sobre o compreender de Ser e Tempo ( $\S 31,32,33)$ deve ser entendido a partir desta vinculação do sentido ao aparecer da "coisa mesma" que concretamente se mostra. Topicamente, no entanto, em amplas zonas do pensamento contemporâneo se tende a interpretar este locus classicus da filosofia do século XX como o estabelecimento, na tradição da filosofia transcendental, de uma instância que conformaria a priori o que pode aparecer. O sentido seria então a figura determinada que as coisas e o mundo têm como resultado das projeções que essa instância (a existência humana, em sua situação concreta), realizaria sobre seu entorno. Por isso se faz necessário, sem entrar em discussão com esta visão, reler esses parágrafos - especialmente o papel da estrutura prévia (Vorstruktur) da compreensão -, a partir deste ângulo da concepção fenomenológica do sentido, que acabamos sucintamente de ver. E isso porque a hermenêutica fenomenológica de Ser e Tempo se mantem balizada pelo âmbito primário do aparecer: é o aparecer das coisas o que tem que ser compreendido e para tanto, 
o mesmo que a fenomenologia transcendental, trata de indagar sobre a estrutura do aparecer, sobre as condições da fenomenalidade. Por isso não pode proceder por hipóteses ou construções mais ou menos imaginativas, mas precisa investigar a partir do que se mostra - quer dizer, a partir do campo básico do sentido - a consistência, a estrutura do fato mesmo do parecer. Um fato que, em Ser e Tempo, é tematizado sob a ideia de "compreensão de ser". O que tal expressão designa, antes que um comportamento determinado da existência humana, é esse lugar do aparecer algo, cuja estrutura formal deve-se investigar. A conhecida resistência de Heidegger a entender a analítica existencial como antropologia vem, a meu entender, daqui: não são os traços antropológicos o que configuram o aparecer, mas, ao contrário, o fato de que as coisas apareçam como sendo elas mesmas o que deve conduzir a compreensão da existência. Por isso, Heidegger, ao invés de "o Dasein humano", dará preferencia à expressão "o Dasein no homem", que reflete com mais claridade a ordem de prioridade: seja lá o que for que constitua a existência humana tem que ser de tal forma que torne possível a manifestação do que "é”. É esta manifestação que dirige a análise do compreender, que não pode então ser inicialmente pensado como um comportamento da subjetividade que se dirige a um mundo e o conforma, senão, ao revés, como o aparecer de um mundo que torna seu e sujeita o compreender.

Podemos entender a determinação hermenêutica do aparecer que realiza Ser e Tempo se nos detivermos a uma segunda referência ao modo grego de considerar as coisas, a que Heidegger alude. Havíamos visto antes como o filósofo de Freiburg mostrava que para os gregos tà ónta (os entes) significava já seu estar manifestos, agora salienta que "os gregos tinham um termo adequado para as 'coisas': as chamavam 'prágmata', que é aquilo com o que alguém tem que se ver no trato da ocupação (práxis)" (HEIDEGGER, Ser e tempo, p. 68). As coisas são consideradas estritamente em seu aparecer ou, como Heidegger gosta de dizer, em seu vir ao encontro (begegnen), aquilo com o que nos ocupamos diretamente ou que tem um determinado papel em nossa ocupação:

$\mathrm{Na}$ abertura e explicação do ser, o ente é o prévia e concomitantemente temático; o tema propriamente dito é o ser. No âmbito da presente análise, o ente pré-temático é o que se mostra no ocupar-se do mundo circundante. Este ente não é então objeto de um conhecimento teorético do "mundo", mas, ao contrário, o usado, produzido, etc (HEIDEGGER, Ser e tempo, p. 67). 
Esta ideia abre o bem conhecido contexto pragmático no qual Heidegger situa toda a sua análise do conceito de mundo. Um contexto que vem dado fenomenológico da cotidianidade: é a imediatidade e a regularidade do habitual, o terreno no qual normalmente aparecem as coisas e nós mesmo com elas. Inclusive o extraordinário tem que contar com a cotidianidade, articulando-se com ela de alguma forma: transformando-a, iluminando-a, etc. Pois bem, desta análise do ente intramundano, se derivam alguns resultados importantes que gravitam sobre o compreender e o sentido, que reúno sinteticamente.

Em primeiro lugar, que o imediato aparecer de algo como esta coisa determinada não se limita ou se fecha nela, mas leva consigo, correalizando-se ${ }^{7}$ com ela, por assim dizer, uma trama de remissões sem a qual não se poderia comparecer no que é. Este último é o essencial, pois o campo de remissões que pulsa na coisa não são relações de justaposição, frente às quais a coisa pudesse permanecer indiferente; nem tampouco relações lineares, que se dessem ao mesmo plano que ela: é um enredado que a situa em um lugar, que a faz visível e que, por sua vez, a constitui como o que é; em uma palavra, que é condição de possibilidade de seu aparecer como precisamente tal coisa. É o que se pretendia mostra o já célebre exemplo do martelo. A articulação Rede-ente intramundano é simultaneamente fenomenológica e ontológica: a rede de referências permite aparecer a coisa e a afeta no que é: a cadeira aparece como a cadeira realmente devido ao dar-se a-temático, não objetivo do campo pragmático ao que pertence. Esta não é uma hipótese, nem uma inferência que fazemos a partir da cadeira, é senão o que se faz presente com ela. Forma, pois, parte do fenômeno e não é uma alcova invisível ou meramente suposta.

Em segundo lugar, o comportamento perceptivo que vê a cadeira, mas também o comportamento que a usa, estão ligados a essa estrutura complexa do aparecer, é mais, formam parte dela: a percepção ou o uso da cadeira o toma imediatamente, sem nenhuma mediação reflexiva ou de outra ordem, como a coisa que é e neste mesmo ato pré-compreende o plano de fundo de referências que determinam sua forma ou tipo de ser (se é "à mão" ou "diante dos olhos"). Como ressalta Heidegger no curso sobre Os problemas fundamentais da fenomenologia, "a intencionalidade da percepção pertence não apenas a intentio e a intentum, mas ainda, à compreensão do modo de ser daquilo ao que se tende no intentum" (HEIDEGGER, GA, 24, p. 100). O que caracteriza essa compreensão "adicionada" é que no ato perceptivo se articula com o percebido como algo que

7N.T.: A palavra usada pelo autor em espanhol foi "co-dándose". Ainda que seja, mesmo em espanhol, um neologismo, me pareceu menos artificial procurar uma palavra que não produzisse tanto estranhamento em português. 
é prévio, que forma uma estrutura prévia ou precedência com respeito à coisa percebida e que não exige outro ato que a cumpra como tal, mas, ao contrário, se dá assim, como condição prévia, no mesmo ato. É esta prioridade constitutiva, acreditada fenomenologicamente na percepção ou no uso, o que o leva a falar de pré-doação ou, caso se queira, pré-percepção. Portanto, o compreender, como comportamento concreto, se ajusta não apenas ao que se percebe, mas ao campo atemático de referências a partir do qual aparece o percebido.

Este pré-ajuste que faz possível os comportamentos concretos e que vive neles é a chave da ideia de projeto, que dá expressão à estrutura existencial do compreender, tal como afirma o $\S 32$. Esta ideia deve ser entendida a partir de este ângulo: que um campo fenomenológico (que permite aparecer) e ontológico (que determina o tipo de ser do que aparece) está já aberto e ao qual está de antemão adscrito todo comportamento. A pré-doação deste campo é o que se subjaz ao projetar, entendido agora como o verter-se dos comportamentos humanos para possibilidade de realização de algo. Justamente porque o que esse campo aberto de referências estabelece é um arco de possibilidades de ser da coisa, que podem ser recorridas pelo comportamento (se pode fazer com ela tal ou tal) tem sentido dizer que este é projeção de possibilidades. Mas o essencial é que essa projeção nem introduz, nem produz o campo de referências, mas antes, supõe um estar de antemão implicado nele. Por isso, Heidegger caracteriza o trato cotidiano com as coisas (prágmata) com o termo bewendenlassen (deixar ser, deixar estar), que, interpretado ontologicamente significa:

\begin{abstract}
o prévio pôr em liberdade do imediatamente à mão dentro do mundo. Deixar "ser" previamente não significa fazer ou produzir o ser de algo, mas descobrir em seu estar à mão algo já "ente" e deixá-lo assim comparecer como o ente deste tipo de ser. Este "apriorístico" deixar ser (bewendenlassen) é a condição de possibilidade para que o à mão com-pareça (HEIDEGGER, Ser e tempo, 85).
\end{abstract}

Que o "estar desde sempre já em um âmbito aberto de referências" se entenda como um deixar ser, como um pôr em liberdade e limpar o terreno para que a coisa possa se mostrar como tal, deixa, a meu entender, poucas dúvidas acerca da pretensão fenomenológica da indagação na Vorstruktur do compreender. Uma pretensão que acentua com nitidez múltiplas formulações heideggerianas nos cursos seguintes a Ser e Tempo. Na Introdução à filosofia, por exemplo, 
Heidegger aponta que "no ser junto a e como tal ser junto a o Dasein leva inicialmente consigo algo assim como um entorno patente ou manifestabilidade" (HEIDEGGER, GA, 27, p. 136). O estar já pré-ajustado à trama de remissões é um aqui ou âmbito de manifestação ao que todo comportamento está vinculado ${ }^{8}$.

O que a análise do trato com o "ente intramundano" revela é o fato fundamental de que o dado, sejam coisas reais, sejam fictícias, objetos isolados ou complexidades de coisas (e também assuntos ou problemas) aparece sempre articulado de maneira concreta em uma estrutura prévia. É esta articulação que o conceito primário de sentido modaliza como manifestabilidade, produzindo o que poderíamos chamar de uma inflexão hermenêutica nele, que expõe de maneira precisa qual é a estrutura do aparecer a qual o sentido se refere. Desta forma, de acordo com Ser e Tempo, sentido é a estrutura formal que articula o compreendido com o campo atemático de remissões no qual se inscreve. A conhecida definição do $\S 32$ é inequívoca: "sentido é o em virtude de que do projeto, estruturado pelo ter, ver e conceber prévios, a partir do qual algo é compreendido como algo" (HEIDEGGER, Ser e tempo, p. 151). Dado que aquilo ao que está sujeito o projeto é ao campo atemático, não ao ente concreto, o "em virtude de" pode ser traduzido por "horizonte", que expressa bem o caráter latente tanto do âmbito de significado prévio quanto da implicação do projeto nele ${ }^{9}$. A noção de sentido de Ser e Tempo da expressão plena a qual o curso de 1925-26 chamava repetidamente a estrutura hermenêutica fundamental do Dasein ${ }^{10}$, cujo "funcionamento" é preciso compreender para determinar por completo o significado e o alcance da noção de sentido.

\subsection{A estrutura hermenêutica fundamental e a questão da significação}

O momento decisivo, no qual se concentra todo o jogo da estrutura hermenêutica, é o "algo enquanto algo". Tal expressão, já tópica, é uma maneira filosófica, teorética, de desentranhar analiticamente aquele ponto no qual propriamente se produz a compreensão de algo determinado, ali onde, ao tratar com o algo ou de algo, tem pleno sentido dizer que "sabemos sobre o que se trata", que o compreendemos. Esse momento é visto por Heidegger como a dobradiça

8 As notas manuscritas de Heidegger no Hüttenexemplar acentuam esta vinculação, ampliando o deixar ser a todo ente, não apenas à mão, de acordo com a revisão que ele empreende em Von Wesen der Wahrheit do compreender e do projeto.

9 Assim o faz Jorge Rivera em sua tradução de Ser e Tempo. Gaos traduz de maneira mais literal como "sobre o fundo de que" (Woraufhin).

10Cf. HEIDEGGER, GA 21, pp. 150, 169, 187. 
na qual se articula (ou melhor, já está articulada) a estrutura prévia atemática com o que em cada caso vem ao encontro. Heidegger acede a sua análise procedendo de duas formas diferentes: em Ser e Tempo o procedimento parte da estrutura ontológica última, o compreender ou o projeto e descende, através da interpretação ou exegese (Auslegung), até o momento final da compreensão, o enunciado; no citado curso Logik, o modo de proceder é inverso, se parte do enunciado como presumido lugar da verdade e se remonta, pelo intermédio da interpretação, ao projeto e o compreender. Em ambos os casos, o algo enquanto algo, que é o núcleo da interpretação, ocupa um lugar medial que não é simplesmente metódico, mas temático: é o momento propriamente estrutural no qual se encadeia a complexidade das partes. Daí a importância de suas análises.

Já vimos que a trama de referências forma parte implícita, latente, do fato imediato da percepção ou do uso de qualquer coisa de nosso entorno: a trama está correalizada (co-dada) com o ente concreto, mas uma co-doação que a análise mostra que tem um sentido preciso, a saber, que a trama se dá como precedendo à coisa, como algo que, distinguindo-se dela, é por sua vez, algo sem o qual não poderia ser o que é. Se o compreendido propriamente é a coisa, a trama de referências é então o pré-compreendido, que tecnicamente é denominado "estrutura prévia" (Vorstruktur). O momento de algo como algo consolida justamente esta articulação entre o dado e o prévio. Naturalmente o desmembramento desta articulação é obra da análise filosófica, que toma essa co-doação da experiência habitual do mundo, na qual é sempre uma compreensão atemática, imediata e irreflexiva. Pois bem, a partir dessa experiência, o momento do prévio não deve ser pensado como um marco conceitual ou uma estrutura lógico-transcendental; o que subministra o horizonte prévio de significação é simplesmente o estar no mundo como "ter a ver com" (Zu-tun-haben-mit) os entes que povoam os múltiplos campos de ação nos quais se realiza a vida.

Eu vivo na compreensão do escrever, do iluminar, do sair e entrar e similares. Ou, mais exatamente: falando, indo, compreendendo, sou, enquanto Dasein, trato compreensivo: meu ser no mundo não é outra coisa senão este se mover já compreensivo nestes modos de ser (HEIDEGGER, GA, 21, p. 146).

Este se mover já compreensivo no âmbito da escritura, a habitação, a cozinha, etc., e em última instância, no mundo como contexto total de possibilidades de 
ação, pelo que tenho constantemente a ver com coisas e assuntos, atua como um "estar sempre já por antecipado junto a algo" e pode se entender por isso um ter de antemão algo como algo, pois esboça um espaço de sentido que antes de que apareça efetivamente algo nele, desenha o tipo de coisas que podem enchê-lo, as quais, desta maneira, recebem antecipadamente a forma geral de sua consistência: é uma cadeira, um lápis, uma frigideira. O que aparece se mostra imediatamente como cadeira, lápis, frigideira, graças a seu prévio estar vinculado ao campo de sentido que antecipa o "como que" vai ser tomado e que se torna efetivo na exegese (Auslegung), quer dizer, na percepção ou nos usos concretos. $\mathrm{O}$ "como que", o algo enquanto algo, expressa rigorosamente a forma de conexão, a síntese ${ }^{12}$ entre o sentido antecipativo e o que efetivamente se dá, pela qual a coisa concreta do caso aparece como tal coisa determinada. Heidegger vê essa conexão como um retornar ou voltar (Zurückkommen) ${ }^{13}$ do âmbito antecipativo ao ente com o qual nos encontramos, ideia que serve bem para realçar a anterioridade lógica do campo de sentido aberto pelo ter-já-a-ver com respeito ao caso concreto de percepção ou de uso de algo, que resulta assim um pleno ato de compreensão. Como aponta Heidegger, se, por hipótese, diante de um simples giz subtraíssemos o momento antecipativo do sentido, ainda que tivéssemos "a mais finamente desenvolvida receptividade sensorial e, além disso, o mais rico acervo de conceitos do entendimento, seguiria sendo incompreensível por toda a eternidade como se chega a ver simplesmente um giz" (HEIDEGGER, GA, 21, p. 148)

Este fenômeno do retorno que acolhe o dado, fazendo-o aparecer como tal coisa determinada, tem uma importância decisiva para nosso problema da noção de sentido, pois nele reside o momento originário da significação, que guarda com ele um evidente parentesco. Como se sabe, em Ser e Tempo, significância (Bedeutsamkeit) é o conceito que reúne a totalidade das relações de remissão estabelecidas entre ser em razão de si mesmo do Dasein, as diversas formas de trato com as coisas em que se exerce e que conformam âmbitos de utilidade, os possíveis empregos, determinados por eles, e a multiplicidade de utensílios ou coisas à mão que lhes seguem. Dela diz Heidegger que "constitui a estrutura do mundo, daquilo em que o Dasein está já sempre enquanto tal $D a$ sein" (HEIDEGGER, Ser e tempo, p. 87). A significação, assim entendida, não

11 "Meu ser próprio como ter a ver com o mundo se ocupando se caracteriza como estar sempre já por antecipado junto a algo" (HEIDEGGER, GA, 21, p. 147)

12 No texto das mencionadas lições de 1925-26 Logik. Die Frage nach der Wahrheit, Heidegger remonta a esta estrutura do algo enquanto algo a unidade de synthesis e diairesis com que Aristóteles caracteriza o logo enunciativo (Cf. HEIDEGGER, GA, 21, p. 149).

13Cf. HEIDEGGER, GA, 21, p. 147-150. 
é primariamente uma rede de significados objetivos, ao modo de um dicionário ou um texto que tivesse que decifrar, mas, ao contrário, está diretamente ligada ao compreender imediato que a existência tem de si mesmo como um poder-ser que tem lugar nos âmbitos de possibilidade de ação que são os setores de utilidade nos quais se move: todas as relações de remissão que conformam a significatividade "estão enlaçadas entre si como uma totalidade originária; são o que são enquanto são este signi-ficar (be-deuten) no qual o Dasein se dá a entender previamente a si mesmo seu estar no mundo" (ibidem). A trama de remissões significa em correlação com um poder-ser nela que desta forma se "significa", quer dizer, se entende a si mesmo como inscrito nessa correlação. Mas o núcleo da significação, o momento no qual uma significação propriamente se origina, se encontra na estrutura de algo como algo, no retorno a partir do âmbito que antecipa um campo de atividades possíveis em direção ao que vem ao encontro, que resulta então em disposição de ser compreendido ${ }^{14}$.

Tudo isso nos serve para esclarecer um segundo momento importante do sentido, o que, além da noção geral de manifestabilidade, o refere a um ente concreto. Se o sentido é "aquilo no que se move a compreensibilidade de algo", a pergunta pelo sentido deste algo não se pode entender que apenas aponta ao plano de fundo de manifestação, representado pela estrutura prévia, mas ao "significado" da coisa concreta: que sentido tem isso? Que significa esta coisa? O sentido concreto de uma coisa, no contexto pragmático no qual opera a análise heideggeriana, é obviamente seu para-que, a função concreta que cumpre em certo âmbito de possibilidade de ação ou de uso e que lhe outorga sua consistência ôntica específica: é uma cadeira, é uma caneca. Essa função, que forma parte intrínseca do que a coisa é, é aberta pela estrutura antecipativa do prévio ter-a-ver, mas não se identifica com ela: o "como que" é tomada a coisa, determinado e preciso, é, por assim dizer, o precipitado do retorno significante, o significado concreto que a coisa recebe ao ser tomada como tal coisa, e que a palavra ${ }^{15}$ conserva e mantem: "cadeira", "caneca". Existe, portanto, um segun-

14 No curso sobre Lógica, várias vezes citado, o fenômeno do significado é simplesmente identificado com o "antecipar-se que retorna sobre algo e ao retornar manifesta": Cf. HEIDEGGER, GA, 21, p. 148.

150 lugar da linguagem (Sprache) e sua relação com a fala ou discurso (Rede) é um dos aspectos menos claros e debatidos de Ser e Tempo. No contexto de nosso problema sobre a noção de sentido, o primordial, o que responde ao mais decisivo da argumentação heideggeriana é recalcar a anterioridade do âmbito do sentido, e da significação aberta por ele, com respeito à expressão em palavras e a fortiori respeito da expressão verbal enunciativa. Tanto no $\$ 34$ como no texto das lições de Lógica de 1925 a palavra segue à significação mundana já compreendida: "A compreensibilidade afetivamente disposta do estar no mundo se expressa como discurso (Rede). $\mathrm{O}$ todo de significações da compreensibilidade vem à palavra. Ȧs significações brotam palavras, em vez de ser as palavras que, entendidas como coisas, estejam (Bedeutung), mas não no sentido habitual do significado de uma palavra, mas que a este significado primário pode agora recair 
do conceito de sentido: a significação determinada que um ente recebe como resultado da estrutura hermenêutica de algo como algo.

\subsection{Recapitulação: a legitimidade do "sentido originário"}

Recapitulemos, para terminar, o conjunto do que foi dito sobre o que chamamos antes a inflexão hermenêutica no sentido como manifestabilidade. Ela consiste, essencialmente, em que a manifestabilidade em geral tem a forma de uma estrutura prévia que acolhe o dado mediante esse retorno significante que é o algo enquanto algo. $\mathrm{O}$ sentido, que se mantém assim plenamente em sua acepção fenomenológica, designa então a totalidade da armação formal (formale Gerüst), o horizonte articulado que permite a visibilidade de algo como coisa determinada. Tal ideia de sentido está enormemente distanciada das concepções que veem nele uma entidade lógico-ideal que se comporia com o sensorialmente dado ou um significado linguístico que revestiria a coisa material. Não se repara suficientemente que Heidegger diz, em pleno acordo com a concepção fenomenológica do sentido, que "o compreendido, tomado estritamente, não é o sentido, mas o ente ou, em seu caso, o ser." (HEIDEGGER, Ser e tempo, p. 151). A percepção, por exemplo, não percebe um sentido, senão esta coisa real e concreta, esta mesa, este copo. O compreendido não é o sentido do copo, senão o copo. A fenomenologia hermenêutica de Heidegger não está interpondo um sentido ou significado linguístico (um noema, como alguns interpretam) entre a coisa e a compreensão, de maneira que o que a faria inteligível seria o

uma palavra." (HEIDEGGER, GA, 21, p. 151). O teor destas linhas é inequívoco: as palavras são a continuação expressiva de uma significação já compreendida no trato com o mundo e, portanto, não o que introduz a significação, como se fosse entidades preexistentes já dotadas dela. As palavras conservam e fixam um significado mundano já compreendido, permitindo assim sua objetivação e a possibilidade de sua compreensão na ausência da situação mundana que o originou. Contudo, no mesmo parágrafo de Ser e Tempo citado, o discurso (Rede), não é considerado como a expressão da compreensibilidade, mas como sua interna e própria articulação, resultando constitutivo do sentido em sua acepção primordial que, como sabemos, cobre o campo inteiro da compreensibilidade. Por isso mesmo é, inclusive, anterior ao momento propriamente significativo da interpretação. Este discurso como "articulação da compreensibilidade" não pode obviamente se identificar com o discurso como expressão verbal, como fala, nem, muito menos, como sua exteriorização objetivada, que é a linguagem. O lugar deste é ainda mais obscuro, sobretudo quando se tem em conta que, quando Heidegger examina, com respeito ao enunciado, sua estrutura prévia, quem aparece fornecendo a conceitualidade prévia (Vorgriff) não é o discurso, mas a linguagem, que até no momento não desempenhara nenhum papel na compreensão. Ver a esse respeito: R. Rodríguez, "El lenguaje como fenomenología" en: Hermenéutica y subjetividad, Madrid, Trotta, 2010; J. Ruiz Fernández, "El Mundo y su supuesta articulación en el Habla: apuntes críticos", Universitas Philosophica, n' 48; W. Anz, "Die Stellung der Sprache bei Heidegger", em: O. Pöggeler (Hrsg), Heidegger. Perspektiven zur Deutung seines Denkens, Königsstein, Atheneum, 1988; C. Lafont. Lenguaje y apertura del mundo: el giro lingüístico en la hermenéutica de Heidegger, Madrid, Alianza, 1997. providas de significações" (HEIDEGGER, Ser e Tempo, p. 161). Este conhecido texto é corroborado por este outro, não menos claro, do citado curso: "O resultado do significar é em cada caso um significado. 
misterioso sentido que habita nela; não há mediação alguma de um sentido para a compreensão. O que há é uma articulação da coisa em um âmbito no seio do qual pode comparecer como a determinada coisa que é. A articulação não proporciona um "sentido" que viesse a se acoplar com algo já dado na coisa, mas, ao contrário, a mostra no que ela é. Seria um mal entendido da segunda acepção de sentido, que acabamos de mencionar, interpretá-la como um significado que a coisa material pré-dada recebe a partir de uma instância linguística ou conceitual. Que uma coisa "tenha sentido" quer dizer apenas que o prévio ter a ver que a afronta "sabe a que ater-se" com ela, para o qual ela se mostrou já como um ente concreto que é. O sentido determinado de uma coisa (sua função ou para-que, seu lugar em um contexto global do mundo) não acrescenta nada a ela, não se superpõem como uma capa de sentido sobre um conjunto de sensações ou de propriedades objetivas, mas a deixa aparecer em seu ser próprio. E nele comparecem (co-aparecem) articuladamente, em remissões determinadas e não justapostas, as propriedades pragmáticas (as das Umweltding) e as propriedade naturais (as das Naturding). Anos mais tarde, mas sem alterar a posição de fundo que estamos vendo, Heidegger dirá com grande claridade que "o compreender é o projeto extático, isto é, o projeto que está lançado dentro do âmbito do aberto. $\mathrm{O}$ âmbito que se entrega como aberto no projetar, para que nele algo (neste caso o ser) se consolide como algo (neste caso o ser como ele mesmo em seu estar desvelado), se chama sentido. 'Sentido de ser' e 'verdade do ser' dizem o mesmo" (HEIDEGGER, GA, 9, p. 377). Uma inequívoca expressão, me parece, do que podemos entender como a marca fenomenológica da inflexão hermenêutica do sentido.

Mas o sentido, como armação formal do aparecer, se realiza sempre em concreto no acontecer histórico da existência. $\mathrm{O}$ que significa que a estrutura prévia e seu contexto de remissões tem em cada caso um conteúdo determinado, conformam esta situação e não outra. É evidente, por exemplo, que o sentido constituído pela armação formal na qual aparece uma mesa não é o mesmo que o de um trenó em uma montanha (ainda que em sua articulação total ambos suponham o mundo, que é, por sua vez, um conceito formal). Esta evidência é a que nos permite, com fundamento, dizer que o trenó "cobra sentido" no contexto de referencias da estepe russa, por exemplo. Mas não nos enganemos, "cobrar sentido" não quer dizer que receba um significado "para nós" (quer dizer, para aqueles que vivem neste contexto) o que antes era uma pura coisa material, mas que o trenó aparece como tal no seu entorno de manifestação e nele é genuinamente trenó. Este momento de genuinidade não é uma questão trivial, pois põem em relevo claramente que a articulação de algo com sua es- 
trutura prévia não é livremente transformável, nem adotada à vontade: dá-se de antemão como já articulada. Justamente por isso, cabe falar em um sentido originário, genuíno, que permite fazer afirmações objetivas (tais como "isto é um trenó") acerca do ser da coisa em questão. Naturalmente é possível retirar algo de seu entorno originário de manifestação e transformar a visão prévia (Vorsicht) o previamente tido (Vorhabe) e dar lhe um "sentido" (na segunda acepção) distinto: posso usar o trenó como suporte para um armário ou como material combustível. Mas isso que é assim usado é já algo determinado (inclusive se ignoro o que seja), algo que se manifestou como tal em seu contexto próprio, pelo qual está perfeitamente justificado falar de um sentido originário no qual a coisa se mostra como é. A possibilidade de substituição ou a transformação dos contextos não anula a intenção primária do sentido que é o deixar que as coisas compareçam como elas mesmas.

\section{Referência Bibliográfica}

ANZ, W., "Die Stellung der Sprache bei Heidegger”, em: O. Pöggeler (Hrsg)

HEIDEGGER, M. Perspektiven zur Deutung seines Denkens, Königsstein, Atheneum, 1988

- Logik. Der Frage nach der Wahrheit. Gesamtausgabe (GA), 21. Frankfurt, Klostermann

.Prolegomena zur Geschichte des Zeitbegriffs. GA, 20.

.Die Grundprobleme der Phänomenologie. GA, 24.

. Einfuihrung in die Philosophie. GA, 27.

Sein und Zeit, Tübingen, Max Niemeyer, 1972

.Wegmarken. GA, 9.

HUSSERL,E.,Logische Untersuchungen, V,VI.Husserliana (Hua), XIX/1, XIX/2. Den Haag, M. Nijhoff . Ideen zu einer reinen Phänomenologie und phänomenologischen Phiosophie I. Hua, III/1
. Erste Philososophie, II. Hua, VIII.

LAFONT, C. Lenguaje y apertura del mundo: el giro lingüístico en la hermenéutica de Heidegger, Madrid, Alianza, 1997

RICOEUR, P., "Phénoménologie et herméneutique: en venant de Husserl...", em Du text à l'action, Paris, Seuil, 1986 RODRÍGUEZ, R., "El lenguaje como fenomenología" em: Hermenéutica y subjetividad, Madrid, Trotta, 2010

La transformación hermenéutica de la fenomenología. Una interpretación de la obra temprana de Heidegger, Madrid, Tecnos, 1997

RUIZ FERNÁNDEZ, J., "El Mundo y su supuesta articulación en el Habla: apuntescríticos", Universitas Philosophica, $\mathrm{n}^{\circ} 48$.

VIGO, A., Arqueologia e aletheiologia, Buenos Aires, Biblos, 2008, 